\title{
Determination of niacin profiles in some animal and plant based foods by high performance liquid chromatography: association with healthy nutrition
}

\author{
Jale Çatak
}

Department of Nutrition and Dietetics, Faculty of Health Sciences, Istanbul Sabahattin Zaim University, Istanbul, Turkey

\begin{abstract}
Vitamin $B_{3}$ (niacin) is essential for all living cells and plays a central role in energy metabolism and oxidative phosphorylation. Vitamin $B_{3}$, a water-soluble vitamin, is present in the form of nicotinic acid and nicotinamide, a monocarboxylic acid derivative of pyridine. While nicotinic acid is commonly effective in lowering cholesterol levels, unlike nicotinic acid, nicotinamide is ineffective on lipids. Presence rates of nicotinic acid and nicotinamide, which are the available forms of vitamin $B_{3}$, are different for each food. However, the studies in the literature are generally based on the analysis of total amount of vitamin $B_{3}$ in foods and the studies determining the profile of vitamin $B_{3}$ in foods are limited. The aim of the study was to determine the vitamin $B_{3}$ profiles of 10 kinds of animal based food and 10 different plant based food samples. In this study, 10 kinds of animal based food samples consisting of veal (veal steak fillet), chicken (breast), turkey meat (thigh), goat meat (leg, belly), lamb (leg, back, arm), mutton (belly), bovine meat (loin) and 10 different plant based food samples namely; barley, rye, wheat (bread), wheat (durum), oat, rice, dried pea, green lentil, red lentil and chickpea were studied by high performance liquid chromatography using post-column derivatization system. The presence rates of nicotinic acid and nicotinamide were determined in the meat samples as $30 \%$ and $70 \%$ and as $87 \%$ and $13 \%$ in the cereal and legume samples, respectively. Nicotinic acid levels were found in low amounts in the meat samples. The amounts of nicotinic acid in the cereal and legume samples were significantly higher than the meat samples. Consequently, the plant based foods such as cereals and legumes, with a ratio of $87 \%$ nicotinic acid presence, standout as the best source of nicotinic acid and encouraging regular intake of those cereals and legumes containing rich nicotinic acid would remove nicotinic acid deficiency in human.

Keywords: Animal based foods, Niacin, Nicotinamide, Nicotinic acid, Plant based foods, Vitamin $\mathrm{B}_{3}$ profiles
\end{abstract}

\section{Background}

Recently, there has been a growing interest in vitamin $\mathrm{B}_{3}$ (niacin) by the emergence of $\mathrm{NAD}^{+}$metabolism in health and disease and the use of nicotinic acid as an important therapy for the treatment of hyperlipidemias [1]. Niacin is an important water-soluble vitamin and monocarboxylic acid derivative of pyridine which found in the nicotinic acid $\left(\mathrm{C}_{6} \mathrm{H}_{5} \mathrm{NO}_{2}\right)$ form and nicotinamide $\left(\mathrm{C}_{6} \mathrm{H}_{6} \mathrm{~N}_{2} \mathrm{O}\right)$ form in foods [2]. The blanket term vitamin $\mathrm{B}_{3}$ is used for both forms. Nicotinic acid (also generally known as niacin) and nico-

Received: Feb 7,2019 Revised: Apr 2, 2019 Accepted: Apr 4, 2019

"Corresponding author: Jale Çatak, Department of Nutrition and Dietetics, Faculty of Health Sciences, Istanbul Sabahattin Zaim University, 34303, Küçükçekmece, Halkalı, Istanbul, Turkey.

Tel: +90-212-692-87-29, E-mail: jalecatak@gmail.com

This is an Open Access article distributed under the terms of the Creative Commons Attribution Non-Commercial License (http://creativecommons.org/licenses/by$\mathrm{nc} / 4.0 /$ ) which permits unrestricted non-commercial use, distribution, and reproduction in any medium, provided the original work is properly cited.

Copyright (C) 2019 Korean Society of Animal Science and Technology. 
tinamide (also known as niacinamide) are similarly effective as a vitamin because they can be converted into each other within the organism [3].

Niacin, first isolated from rice bran in 1911, is readily metabolized and excreted vitamin with a recommended daily allowance of 14-16 mg/day [4]. It was later recognised to have two distinct but chemically related components, nicotinic acid and nicotinamide.

Vitamin $\mathrm{B}_{3}$, in the form of the dinucleotides, is essential for all living cells and plays a central role in energy metabolism and oxidative phosphorylation and required for protein, fat and carbohydrate metabolism in the whole organism. Niacin perform important metabolic roles in living cells as a precursors of $\mathrm{NAD}^{+} / \mathrm{NADH}$ and $\mathrm{NADP}^{+} / \mathrm{NADPH}$ [5]. With this metabolic cofactor effect, it is actively involved in preventing many pathological processes. Its deficiency causes the disease called as "pellagra" in man which is characterized by the rough or raw skin. Other problems include memory loss, vomiting and diarrhea. Niacin deficiency is also associated with an increased risk of cancer [6]. and has been shown to increase toxicity caused by reactive oxygen species [7].

B-complex vitamins that are not stored in the body, but should be taken into body daily [8]. A small amount of the niacin can be synthesized from the dietary amino acid tryptophan, but most of the daily requirement must be met by external sources of niacin [9]. The amount of niacin in the body is expressed in $\mathrm{mg}$ as nicotinic acid $(\mathrm{mg})+$ nicotinamide $(\mathrm{mg})+1 / 60$ tryptophan $(\mathrm{mg})$. Additionally, riboflavin converts the amino acids into niacin $[4,10,11]$. In addition to being nutrients, nicotinamide and nicotinic acid are clinically applied pharmacological agents. Nicotinic acid is the oldest drug used to treat dyslipidemia. Very high intakes of niacin, many times larger than the conventionally accepted vitamin levels, are used clinically: nicotinic acid as a hypolipidaemic-hypocholesterolaemic agent [12], and nicotinamide in the treatment of schizophrenia [13] and other psychiatric disorders. Clinical studies have shown that nicotinic acid therapy reduces the number of cardiac and the fatal heart diseases $[14,15]$ and should be given in high doses for the lipid-lowering effect. Diet is considered an important factor for the development of dyslipidemia. [16]. Blood total cholesterol (TC) and low-density lipoprotein (LDL) correlate strongly with coronary heart disease. Hypercholesterolemia is an abnormally high amount of cholesterol in the blood. One of the main effect of nicotinic acid associated with reduced lipids (low density lipoproteins, fatty acids and cholesterol) [16,17].

Nicotinamide, first isolated from horse erythrocytes in 1935, is the amide derivative of nicotinic acid [18]. While nicotinic acid is commonly effective in lowering cholesterol levels, unlike nicotinic acid, nicotinamide is ineffective on lipids.

Niacin is required to be taken with foods and found in various plant based and animal based food sources. Good sources of niacin include yeast, meat, poultry, red fish (e.g., tuna, salmon), cereals, legumes, and seeds. Milk, green leafy vegetables, coffee and tea also provide some niacin [19]. In plants, especially mature cereal grains like corn and wheat, niacin may be bound to sugar molecules in the form of glycosides, which significantly decrease its bioavailability [20]. During the cooking of cereals, particularly in products that are slightly alkaline by the use of baking soda, the availability of niacin increases [21].

In the literature, foods are associated with hypercholesterolemia in lowering cholesterol and it has been proven that foods with these ingredients to carry a health claim indicating that they reduce the risk of cardiovascular disease [22-26]. The best way to get the daily requirement of essential vitamins is to eat a balanced diet that contains a variety of foods. Thus, loss or changes of nicotinic acid and nicotinamide acid in foods also should be taken under control during food process or storage conditions. Knowing the profile of vitamin $\mathrm{B}_{3}$ is important in many ways such as in the preparation of a complete food composition table, preparation of diet therapy, nutrition education, food security, safety and regulation, food based dietary guidelines, labelling of food in the food industry, nutritional survey and also for other research purposes.

Presence rates of nicotinic acid and nicotinamide, which are the available forms of vitamin $\mathrm{B}_{3}$, are different for each food. However, the studies in the literature are generally based on the analysis of total amount of vitamin $\mathrm{B}_{3}$ in foods [27-30] and the studies determining the profile of vitamin $\mathrm{B}_{3}$ in foods are limited [2,21,31-36]. Therefore, the aim of the study was to investigate the presence and levels of vitamin $B_{3}$ in some animal based and plant based foods for determining their vitamin $\mathrm{B}_{3}$ profiles in these foods which have been proven to have positive effects on health particularly on blood lipid level.

\section{Materials and Methods}

This study has focused on the vitamin $\mathrm{B}_{3}$ profiles of some animal based foods and plant based foods. Post-column UV derivatization system by HPLC (high-performance liquid chromatography) was used to determine the presence and concentrations of nicotinic acid and nicotinamide in the 20 food samples consisting of 10 meat samples and 10 cereal and legume samples. In this study, 10 kinds of animal based food samples consisting of veal (veal steak fillet), chicken (breast), turkey meat (thigh), goat meat (leg, belly), lamb (leg, back, arm), mutton (belly), bovine meat (loin) and 10 different plant based food samples namely; barley, rye, wheat (bread), wheat (durum), oat, rice, dried pea, green lentil, red lentil and chickpea were studied. 


\section{JAST}

\section{Reagents and materials}

The vitamin standards (nicotinic acid and nicotinamide) and teflon tube "tubing" (length: $20 \mathrm{~m}$ diameter: $0.5 \mathrm{~mm}$ ), used in this study, were obtained from Sigma-Aldrich (St. Louis, MO, USA). UVA lamp (20 W, $60 \mathrm{~cm}$ ) was used for post-column derivatization. Sodium hydroxide $(\mathrm{NaOH})$, hydrochloric acid $(\mathrm{HCl})$, hydrogen peroxide $\left(\mathrm{H}_{2} \mathrm{O}_{2}\right)$, copper sulfate $\left(\mathrm{CuSO}_{4}\right)$, trichloroacetic acid $\left(\mathrm{C}_{2} \mathrm{HCl}_{3} \mathrm{O}_{2}\right)$ and potassium dihydrogen phosphate $\left(\mathrm{KH}_{2} \mathrm{PO}_{4}\right)$ were obtained from Sigma (St. Louis, MO, USA). In this study, all other chemicals were used in high purity.

Samples of veal (veal steak fillet), chicken (breast), turkey meat (thigh), goat meat (leg, belly), lamb (leg, back, arm), mutton (belly), bovine meat (loin), barley, rye, wheat (bread), wheat (durum), oat, rice, dried pea, green lentil, red lentil and chickpea were purchased from local markets in Turkey and grounded in the laboratory.

\section{Instrumentation}

The profile of vitamin $\mathrm{B}_{3}$ was determined by HPLC, consisting of Shimadzu Nexera-İ LC-2040C 3D pump with a Shimadzu RF20A fluorescence detector (Shimadzu Corporation, Kyoto, Japan) according to the procedure described by Lahely et al. with some modifications [37]. The Zorbax eclipse X08-C18 column (5 $\mu \mathrm{m}, 4.6$ $\times 150 \mathrm{~mm}$ ) (Agilent, USA) was used and the flow rate was $1 \mathrm{~mL} /$ min. The column oven temperature was maintained at $25^{\circ} \mathrm{C}$, the analysis time was $40 \mathrm{~min}$ and the injection volume was $20 \mu \mathrm{L}$.

\section{Standard preparation}

Standard stock solution of nicotinic acid and nicotinamide (100 $\mu \mathrm{g} / \mathrm{mL}$ ) was prepared in $0.1 \mathrm{~N} \mathrm{HCI}$ solution. Each standard is freshly prepared daily. Working standards in five concentration levels were prepared from stock solution.

\section{Sample preparation}

Homogenized 1-10 $\mathrm{g}$ of the samples (based on the estimated amount of niacin it may contain) were placed in $100 \mathrm{~mL}$ erlene, then $60 \mathrm{~mL}$ of $0.1 \mathrm{~N} \mathrm{HCI}$ was added and autoclaved at $121^{\circ} \mathrm{C}$ for 30 minutes. Then, the samples were taken from the autoclave and cooled down to room temperature, $2 \mathrm{~mL}$ of $20 \%$ tricycloacetic acid $\left(\mathrm{C}_{2} \mathrm{HCl}_{3} \mathrm{O}_{2}\right)$ solution was added to the solution, proteins were precipitated, the volume was completed with $0.1 \mathrm{~N} \mathrm{HCI}$, filtered through filter paper. The final solution filtered through $0.45 \mu \mathrm{m}$ filter into HPLC vials.

\section{HPLC determination of nicotinic acid and nicotinamide profiles of vitamin $B_{3}$}

Post-column derivatization is required to determine the profile of vitamin $\mathrm{B}_{3}$. For post-column derivatization, a photo-chemical derivatization system was established in the laboratory. Detection methods described by Lahely et al. was used with some modifications [37]. The derivatization system was made by wrapping a teflon tubing with a length of $20 \mathrm{~m}$ and a diameter of $0.5 \mathrm{~mm}$ on a UV-A lamp $60 \mathrm{~cm}$ long. The system was connected between the analytical column and the fluorescence detector. The mobile phase prepared daily and protected from light. The mobile phase was prepared by mixing $500 \mathrm{~mL}$ of deionized water and $9.5 \mathrm{~g}$ of potassium dihydrogen phosphate $\left(\mathrm{KH}_{2} \mathrm{PO}_{4}\right)$. Then, $7.5 \mathrm{~mL}$ of hydrogen peroxide $\left(\mathrm{H}_{2} \mathrm{O}_{2}\right)$ and $2 \mathrm{~mL}$ of copper (II) sulfate solution $\left(\mathrm{CuSO}_{4}\right)$ (0.12 copper (II) dissolved in $100 \mathrm{~mL}$ of deionized water) was added and the volume was completed with $1 \mathrm{~L}$ of deionized water. Finally, the mobile phase was filtered through a $0.22 \mu \mathrm{m}$ filter. The fluorescence detector set to excitation wavelength of $322 \mathrm{~nm}$ and emission wavelength of $380 \mathrm{~nm}$, respectively. An Agilent eclipse X08-C18 column (5 $\mu \mathrm{m}, 4.6 \times 150 \mathrm{~mm}$, Agilant Technologies) was used and flow rate of $1 \mathrm{~mL} / \mathrm{min}$. The injection volume was set at $20 \mu \mathrm{L}$, and separation was completed in $40 \mathrm{~min}$.

\section{Results and Discussion}

\section{Method validation, quantification and quality control}

Linearity was evaluated by analysing five different concentrations of standard solutions in triplicate.

The calibration curve was obtained in a concentration range from $1 \mu \mathrm{g} / \mathrm{mL}$ to $10 \mu \mathrm{g} / \mathrm{mL}$ and found to be linear for nicotinic acid and nicotinamide with coefficient of determination greater than 0.996 as shown in Table 1.

Limit of detection (LOD) and limit of quantification (LOQ) for nicotinic acid and nicotinamide were calculated from the calibration line at the lowest concentration using the following equations: $\mathrm{LOD}=3 \times \mathrm{SD}, \mathrm{LOQ}=10 \times \mathrm{SD}$, (SD: standard deviation). LOD and LOQ values have been shown in the Table 1.

Dried pea sample was used for precision and accuracy assess-

Table 1. Results for validation parameters (Dried pea)

\begin{tabular}{lcc}
\hline & Nicotinic acid & Nicotinamide \\
\hline Linear regression equation & $y=371,678 x-$ & $y=649,469 x+$ \\
& 106,410 & 33,576 \\
$r^{2}$ & 0.9979 & 0.9978 \\
Range of linearity $(\mu \mathrm{g} / \mathrm{mL})$ & $1-10$ & $1-10$ \\
Repeatability $(\mathrm{RSD}, \mathrm{n}=10)$ & $2.0 \%$ & $2.0 \%$ \\
$\begin{array}{l}\text { Reproducibility }(\mathrm{RSD} \text { of intra-day } \\
\text { studies, } \mathrm{n}=16)\end{array}$ & $2.08 \%$ & $2.04 \%$ \\
$\mathrm{LOD}(\mu \mathrm{g} / \mathrm{mL})$ & 0.005 & 0.004 \\
LOQ $(\mu \mathrm{g} / \mathrm{mL})$ & 0.018 & 0.013 \\
$\begin{array}{l}\text { Accuracy }(\mathrm{a}, \text { recovery; } \mathrm{b}, \mathrm{RSD} ; \\
\mathrm{n}=10)\end{array}$ & $104.2 \%^{\mathrm{a}}, 0.34 \%{ }^{\mathrm{b}}$ & $96.4 \%{ }^{\mathrm{a}}, 0.28 \%{ }^{\mathrm{b}}$ \\
\hline
\end{tabular}

$x$, amount $(\mu \mathrm{g} / \mathrm{mL}) ; y$, peak area; $r^{2}$, correlation coefficient;

LOD, limit of detection; LOQ, limit of quantification; RSD, relative standard deviation. 
ment in the study. The precision study of the analytical method included repeatability and reproducibility tests. The repeatability was tested by analysing the same sample in ten replicate within the same day. The reproducibility was determined by analysing the same sample in 16 replicates in three independent days. The relative standard deviation (RSD) values of repeatability are $2.0 \%$ and $2.0 \%$ respectively, RSD values of reproducibility are $2.08 \%$ and $2.04 \%$ respectively, for nicotinic acid and nicotinamide as shown in Table 1.

The accuracy of the method was evaluated by analysing the Standard Reference Material 1849a, Infant/Adult Nutritional Formula $(108 \pm 10 \mathrm{mg} / \mathrm{kg})$, demonstrating the validity of the assays. The recoveries for the dried pea sample was determined by spiking standard solution at concentration of $0.5 \mu \mathrm{g} / \mathrm{mL}$. Recoveries were found to be in the range of $96.4 \%$ and $104.2 \%$ for nicotinamide and nicotinic acid respectively, as shown in Table 1.

Blank samples of ultrapure water and reagents were also prepared using the same procedures as for the food samples. In the determination of nicotinic acid and nicotinamide no obvious interferences was observed from the blank chromatograms.

The quality procedures of analytical method were based on ISO/ IEC 17025 requirements. A Standard Reference Material (SRM 1849a) Infant/Adult Nutritional Formula was provided from $\mathrm{Na}$ tional Institute of Standards \& Technology (Gaithersburg, MD, USA) and was proceed in a similar way to the unknown samples.

For the quality of the research, we participated in the FAPAS ${ }^{\circledR}$ test (2018), the proficiency test for analysing breakfast cereal, which organized by FAPAS ${ }^{\circledR}$ (Food Analysis Performance Assessment Scheme in UK). All analyses performed in triplicate, and the average value used. Our result was found in the acceptable range ( -2 $\leq \mathrm{Z}$ score $\leq+2)$.

\section{Profiles of vitamin $\mathrm{B}_{3}$}

HPLC is one of the most convenient and accurate analytical techniques to analyze the vitamin $\mathrm{B}_{3}$ from foodstuffs. The results indicating nicotinic acid and nicotinamide acid concentrations given in Table 2 for some animal based foods such as meat and HPLC chromatograms of the standard and the goat meat (belly) sample presented in Fig. 1 and 2. Table 3 shows the vitamin $B_{3}$ profiles of some plant based foods such as cereals and legumes.

\section{Vitamin $B_{3}$ profiles of some animal based foods}

The analytical method was successfully applied to determine the vitamin $B_{3}$ profile of 10 meat samples; veal (veal steak fillet), chicken (breast), turkey meat (thigh), goat meat (leg, belly), lamb (leg, back, arm), mutton (belly), bovine meat (loin), and the results are shown in Table 2.

Fig. 1 and 2 show typical chromatograms for standard solution and the goat meat (belly) sample, respectively.

The concentrations of nicotinic acid were found in the range of values between $8.5 \%$ and $49.6 \%$ in the meat samples while the concentrations of nicotinamide were found between 59\% and 91.5\%. Nicotinic acid form and nicotinamide form were found together in all meat samples.

Among the samples, the highest amount of nicotinic acid was found in chicken breast with $3.739 \mathrm{mg} / 100 \mathrm{~g}$. However, since the chicken breast sample also contained $5.442 \mathrm{mg} / 100 \mathrm{~g}$ nicotinamide, the concentration of nicotinic acid was listed in the third as a percentage. In terms of the nicotinic acid profile, the highest amount of nicotinic acid was found in the chicken breast sample in a quantitative amount among the meat samples, but the highest percentage was the lamb arm sample. The lamb arm sample contains $2.112 \mathrm{mg} / 100 \mathrm{~g}$ nicotinic acid, but also contains 2.143 $\mathrm{mg} / 100 \mathrm{~g}$ nicotinamide so the presence of nicotinic acid and

Table 2. Vitamin $B_{3}$ profiles of some animal based foods

\begin{tabular}{|c|c|c|c|c|c|}
\hline Animal based food samples & $\begin{array}{l}\text { Nicotinic acid } \\
(\mathrm{mg} / 100 \mathrm{~g})\end{array}$ & $\begin{array}{c}\text { Nicotinamide } \\
(\mathrm{mg} / 100 \mathrm{~g})\end{array}$ & $\begin{array}{c}\text { Total } \\
(\mathrm{mg} / 100 \mathrm{~g})\end{array}$ & $\begin{array}{c}\text { Nicotinic acid } \\
(\%)\end{array}$ & $\begin{array}{c}\text { Nicotinamide } \\
(\%)\end{array}$ \\
\hline Veal (veal steak fillet) & 3.032 & 6.650 & 9.682 & 31.3 & 68.7 \\
\hline Chicken (breast) & 3.739 & 5.442 & 9.181 & 40.7 & 59.3 \\
\hline Turkey meat (thigh) & 3.600 & 5.575 & 9.175 & 39.2 & 60.8 \\
\hline Goat meat (leg) & 0.751 & 5.226 & 5.977 & 12.6 & 87.4 \\
\hline Goat meat (belly) & 1.036 & 3.970 & 5.006 & 20.7 & 79.3 \\
\hline Lamb (leg) & 2.366 & 3.405 & 5.771 & 41 & 59 \\
\hline Lamb (back) & 0.424 & 4.586 & 5.010 & 8.5 & 91.5 \\
\hline Lamb (arm) & 2.112 & 2.143 & 4.255 & 49.6 & 50.4 \\
\hline Mutton (belly) & 1.680 & 4.008 & 5.688 & 29.5 & 70.5 \\
\hline Bovine meat (loin) & 1.480 & 4.185 & 5.665 & 26.1 & 73.9 \\
\hline Mean & & & & 29.9 & 70.1 \\
\hline
\end{tabular}


$\mathrm{mV}$

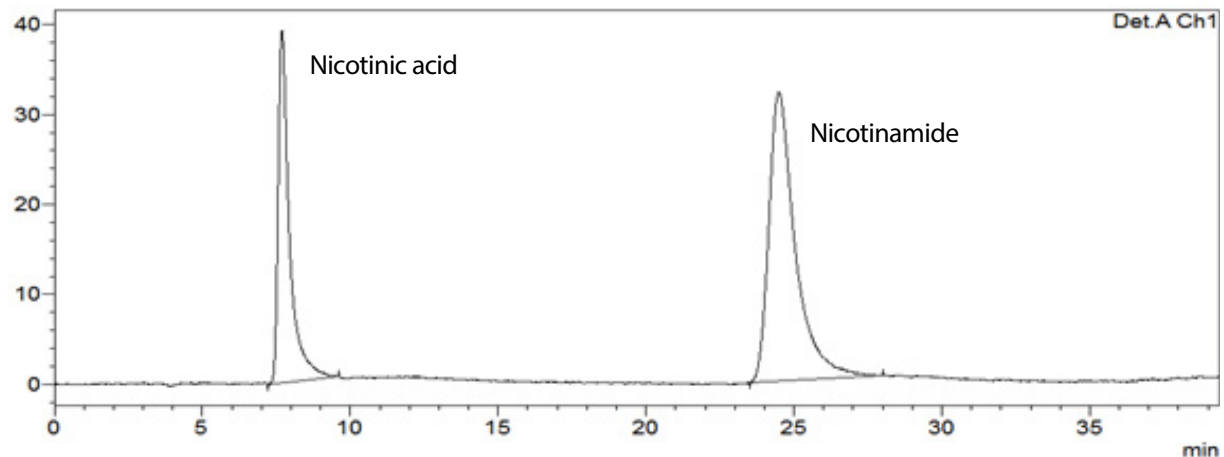

Fig. 1. HPLC chromatogram of the standard for nicotinic acid and nicotinamide.

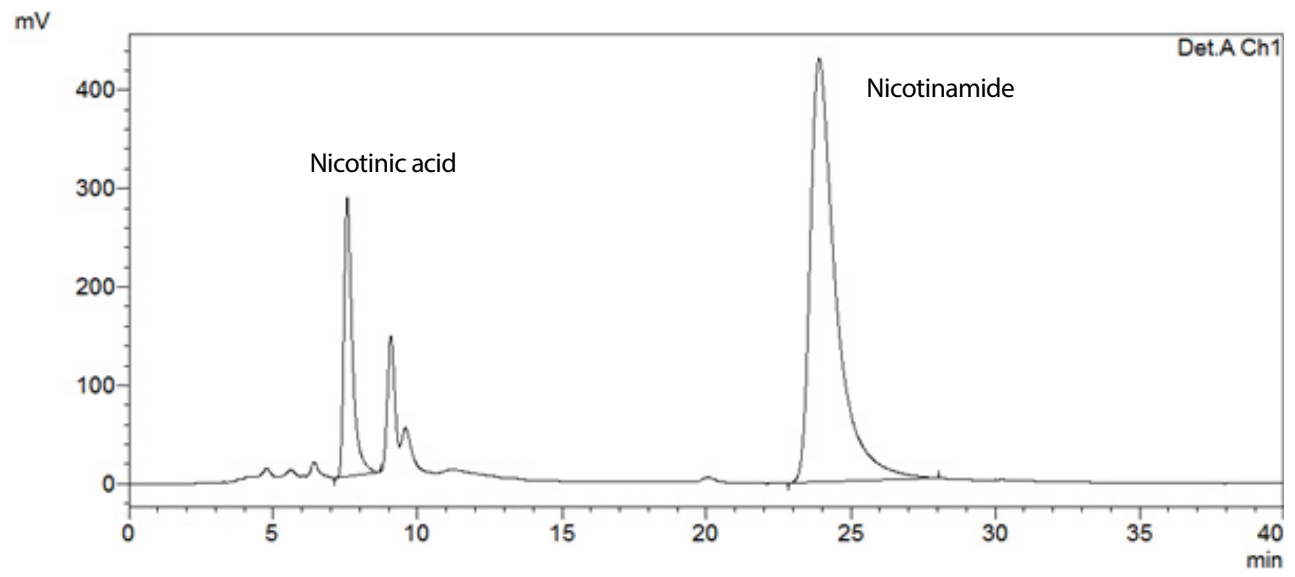

Fig. 2. HPLC chromatogram of the goat meat (belly) sample for nicotinic acid and nicotinamide under chromatographic conditions of the analytical method.

nicotinamide in the lamb arm was found to be $49.6 \%$ and $50.4 \%$ respectively.

The lowest amount of nicotinic acid in the samples was the lamb back with $0.424 \mathrm{mg} / 100 \mathrm{~g}$ and $8.5 \%$. If we list the nicotinic acid levels in the meat samples from high to low; chicken (breast), turkey meat (thigh), veal (veal steak fillet), lamb (leg), lamb (arm), mutton (belly), bovine meat (loin), goat meat (belly), goat meat (leg) and lamb (back), respectively.

Another remarkable point is that the nicotinic acid levels in the meat samples differed in the meats belonging to the different regions of the animal. However, when comparing the amounts of nicotinic acid in the meat samples belonging to a region of the an-

Table 3. Vitamin $B_{3}$ profiles of some plant based foods

\begin{tabular}{|c|c|c|c|c|c|}
\hline Plant based food samples & $\begin{array}{l}\text { Nicotinic acid } \\
(\mathrm{mg} / 100 \mathrm{~g})\end{array}$ & $\begin{array}{c}\text { Nicotinamide } \\
(\mathrm{mg} / 100 \mathrm{~g})\end{array}$ & $\begin{array}{c}\text { Total } \\
(\mathrm{mg} / 100 \mathrm{~g})\end{array}$ & $\begin{array}{c}\text { Nicotinic acid } \\
(\%)\end{array}$ & $\begin{array}{c}\text { Nicotinamide } \\
(\%)\end{array}$ \\
\hline Barley & 4.523 & - & 4.523 & 100 & 0 \\
\hline Rye & 4.168 & - & 4.168 & 100 & 0 \\
\hline Wheat (bread) & 5.483 & - & 5.483 & 100 & 0 \\
\hline Wheat (durum) & 6.668 & - & 6.668 & 100 & 0 \\
\hline Oat & 1.025 & - & 1.025 & 100 & 0 \\
\hline Rice & 1.767 & - & 1.767 & 100 & 0 \\
\hline Dried pea & 1.150 & 2.631 & 3.781 & 30.4 & 69.6 \\
\hline Green lentil & 4.127 & - & 4.127 & 100 & 0 \\
\hline Red lentil & 2.204 & 0.478 & 2.682 & 82.2 & 17.8 \\
\hline Chickpea & 1.681 & 1.412 & 3.093 & 54.3 & 45.7 \\
\hline Mean & & & & 86.7 & 13.3 \\
\hline
\end{tabular}


imal, it is also wrong to make a generalization. For example, while in 3 different lamb meat samples, the highest amount of nicotinic acid (mg/100 g) was found in lamb leg, in goat belly meat the amount of nicotinic acid was higher than goat leg meat.

\section{Vitamin $B_{3}$ profiles of some plant based foods}

The analytical method was successfully applied to determine the vitamin $\mathrm{B}_{3}$ profile of 10 cereal and legume samples; barley, rye, wheat (bread), wheat (durum), oat, rice, dried pea, green lentil, red lentil and chickpea, and the results are shown in Table 3.

In the cereals and legumes samples, the amounts of nicotinic acid were in the range of $30.4 \%$ to $100 \%$ and the nicotinamide concentrations were between $0 \%$ and $69.6 \%$. In 10 plant based food samples, the highest amount of nicotinic acid containing sample was the durum wheat with $6.668 \mathrm{mg} / 100 \mathrm{~g}$, while the lowest nicotinic acid containing sample was the oat with $1.025 \mathrm{mg} / 100 \mathrm{~g}$.

The presence and amounts of nicotinic acid of the samples in mg per $100 \mathrm{~g}$ from high to low, wheat (durum), wheat (bread), barley, rye, green lentil, red lentil, rice, chickpea, dried pea and oat, respectively. When we assess in terms of the profile, 7 of 10 samples (barley, rye, wheat (bread), wheat (durum), oat, rice, green lentil) did not contain nicotinamide and as a consequence the concentration of nicotinic acid in these samples was 100\%. In 70\% of the cereal and legume samples was observed that only nicotinic acid form was present (there were only nicotinic acid form). While 70\% of the cereal and legume samples were not in nicotinamide form, in 3 samples (dried pea, red lentil, chickpea) nicotinic acid form and nicotinamide form were seen together.

While the nicotinamide form was either absent or low level from nicotinic acid form throughout the samples, only in the pea sample the amount of nicotinamide was more than 2 times than the amount of nicotinic acid in quantity.

In consistent with the results of this study for the lamb meat total niacin content in the range of $4.3-5.8 \mathrm{mg} / 100 \mathrm{~g}$, Williams reported in his study that $5.2 \mathrm{mg} / 100 \mathrm{~g}$ total niacin for the lamb meat in nutrient composition (per $100 \mathrm{~g}$ ) of lean red meat list in the 'Nutritional composition of red meat' study [30].

According to the Table 3, we can say that the cereals and legumes are the best sources of nicotinic acid. Although nicotinic acid form and nicotinamide form were present together in the all meat samples, in $70 \%$ of cereal and legume samples, only nicotinic acid form was present.

In the cereal and legume samples, nicotinic acid concentrations were found to be significantly higher than the meat samples. Nicotinic acid concentrations were found in low amounts in the meat samples. Nicotinamide concentrations were much higher than nicotinic acid concentrations in all meat samples. The presence rates of nicotinic acid and nicotinamide were determined in the meat samples as $30 \%$ and $70 \%$ and as $87 \%$ and $13 \%$ in the cereal and legume samples, respectively.

As can be clearly seen from Table 2 and 3, in terms of vitamin $\mathrm{B}_{3}$ profile, the profile in the meat samples appears as a combination of nicotinic acid and nicotinamide while the profile in the cereal and legume samples show the predominant characteristic of nicotinic acid with $100 \%$ nicotinic acid form in $70 \%$ of the samples.

Nicotinic acid has been proven to have positive effects on blood lipid level. Clinically, high-dose nicotinic acid leads to reduced lipidemias, reduced progression of coronary heart disease, and reduced mortality [16]. Dyslipidemia is the abnormal lipid metabolism which is regarded as a strong predictor for the development of cardiovascular diseases (CVDs) and one of the most important risk factors for cardiovascular disease and diet is considered an important factor for the development of dyslipidemia [18].

Ahmad has been reported that incorporation of lentils in human diets may help in protection and management of CVDs and related disorders according to the results of the study which investigates the effects of lentil on serum lipidemia and cardiovascular indexes in cholesterol-fed rats [38].

Niacin is a type of B vitamin and is also important for converting food to energy. It is water-soluble, which means it is not stored in the body and leftover amounts of the vitamin leave the body through the urine. That means human need a regular supply of vi$\operatorname{tamin} \mathrm{B}_{3}$ in their diet.

In the literature, there are studies based on total niacin content of foods. The results of this study were compared with the US Department of Agriculture Nutrient Database and Turkish Food Composition Database. For example, for the wheat (durum), total niacin content was found $6.668 \mathrm{mg} / 100 \mathrm{~g}$ in this study. In consistent with the findings of this study, according to the USDA, total niacin content of wheat (durum) is $6.738 \mathrm{mg} / 100 \mathrm{~g}$ in National Nutrient Database [39]. In addition, according to Turkish Food Composition Database (TURCOMP), total niacin content of wheat (durum) $6.650 \mathrm{mg} / 100 \mathrm{~g}$ [40].

In the literature, niacin sources are generally reported as meat, fish and poultry etc., but in particular their profiles should also be taken into account. The results of the analysis showed that the total niacin content of meat samples was high but, their profiles say many other things, the profiles showed a very valuable information as the levels of nicotinic acid were low.

Jenkins et al., stated that the National Cholesterol Education Program Adult Treatment Panel III (ATP III) and the American Heart Association have been recommended the use of functional foods or foods high in components that reduce cholesterol as additional options to enhance the effectiveness of cholesterol-lowering diets to increase the relevance of dietary advice for the primary prevention of cardiovascular disease. These functional foods and 


\section{JAST}

components include viscous fibers, soy protein, plant sterols, and nuts. Jenkins et al., have been assessed the efficacy of these cholesterol-lowering components when combined in the same diet to determine whether predicted reductions in LDL cholesterol of 30\% could be achieved by diet, in a series of metabolically controlled studies. They found that, more than $30 \%$ of motivated participants who ate the dietary portfolio of cholesterol-lowering foods under real-world conditions have been able to lower LDL-cholesterol concentrations $>20 \%$, which has not been significantly different from their response to a first-generation statin taken under metabolically controlled conditions [25].

Chen et al., also summarized in their review that the findings of recent studies on the production, application, efficacy, and mechanisms of popular cholesterol-lowering nutraceuticals and functional foods. According to them; a nutritionally balanced diet that reduces saturated fat and cholesterol intake has traditionally been the first goal of dietary therapy in lowering plasma TC and recently nutraceuticals and functional foods have attracted much interest as possible alternative therapies for lowering plasma TC, especially for hypercholesterolemia patients, whose blood cholesterol level is marginally high (200-240 mg/dL) but not high enough to warrant the prescription of cholesterol-lowering medications [27].

As it is well known, the soluble fiber in foods reduces the concentration of elements required for cholesterol synthesis in the liver by inhibiting the absorption of bile acids in the intestine. In addition, gamma tocopherol, which is found in fiber sources such as oats, barley, rice husks, reduces serum cholesterol by preventing cholesterol synthesis in the liver. Shamliyan et al. reported that the presence of 5-10 $\mathrm{g}$ soluble fiber in daily diet reduces the risk of cardiovascular disease and death and consuming foods rich in viscous soluble fiber reduces LDL cholesterol blood levels $10 \%$ to $15 \%$ with expected reduction in CVD events by $10 \%$ to $15 \%$ [26].

Mclntosh et al., studied the influence of two sources of dietary fiber (nonstarch polysaccharides, NSP) on blood lipids and glucose concentrations. 21 mildly hypercholesterolemic men aged 30-59 $\mathrm{y}$ have been provided with comparable barley and wheat foods for each of 4 week in a crossover-designed experiment. Barley contains $\beta$-glucan as a source of soluble dietary fiber whereas wheat contains the largely insoluble cellulose and hemicellulose fiber. Consumption of barley relative to wheat foods has been associated with a significant fall in both plasma TC $(6 \%, p<0.05)$ and in low-density-lipoprotein cholesterol $(7 \%, p<0.02)$ whereas triglyceride and glucose concentrations has not been changed significantly. They have been concluded that barley dietary fiber is more effective than wheat dietary fiber at lowering blood cholesterol in hypercholesterolemic men [24].

Kirby et al. suggested that palatable and inexpensive high-fiber foods such as oat bran may have a role in the treatment of certain patients with hypercholesterolemia. They have been fed control and oat-bran diets in an alternating sequence to eight men with previously documented hypercholesterolemia to evaluate selected metabolic effects of plant fibers. They found that serum TC concentrations were stable on control diets whereas a progressive reduction was observed in seven men on oat-bran diets. On oat-bran diets, average reductions in serum TC concentrations found $13 \%(p$ $<0.01, \mathrm{n}=8$ ); plasma LDL cholesterol concentrations found $14 \%$ lower $(p<0.05)$ while high-density lipoprotein cholesterol concentrations have not been changed [23].

Health is vital for sustaining life and a healthy, adequate and balanced diet is essential for the preservation and maintenance of health. In order to have a healthy diet, everyone needs to know the nutritional composition of the foods they eat, as well as the amount of important vitamins and their profiles in the nutrients. In literature, no recent data is available about the profiles of vitamin $B_{3}$ of foods such as meat, cereal and legume that are eaten everyday by human. Moreover, numerous people frequently suffer from lack of nicotinic acid in their daily diets like people with high blood cholesterol levels. Nicotinic acid deficiency is one of the major dietary problems of people with hypercholesterolemia. People usually think they meet the needs of nicotinic acid by consuming meat, fish and poultry etc.in their daily diet, because of vitamin $B_{3}$ is often referred to as nicotinic acid in the literature, which are known as vitamin $\mathrm{B}_{3}$ rich foods.

\section{Conclusion}

Niacin has many important biological functions in humans and we need to have more detailed and accurate information about it therefore, the determination of niacin profiles in biological samples is important for evaluating nutritional conditions. This study was conducted in order to determine the vitamin $\mathrm{B}_{3}$ profiles of 10 kinds of animal based food and 10 different plant based food samples by HPLC using post-column derivatization system. There is no available data and comprehensive study published in the literature regarding the vitamin $\mathrm{B}_{3}$ profile in meats, cereals and legumes. This study will provide the vitamins $B_{3}$ profile of some animal based foods and some plant based foods. However, this study reported of vitamin $\mathrm{B}_{3}$ profiles in a limited number of samples and hopefully, these new values will serve as a useful means to calculate dietary intake of vitamin $\mathrm{B}_{3}$ in the general population. These data will also be useful in the preparation of a complete food composition table, preparation of diet therapy, food based dietary guidelines, nutrition education, food security, safety and regulation, labelling of food in food industry, nutritional survey and also for other research aims. 


\section{Competing interests}

No potential conflict of interest relevant to this article was reported.

\section{Funding sources}

Not applicable.

\section{Acknowledgements}

Not applicable.

\section{Availability of data and material}

Upon reasonable request, the datasets of this study can be available from the corresponding author.

\section{Authors' contributions}

The article is prepared by a single author.

\section{Ethics approval and consent to participate}

This article does not require IRB/IACUC approval because there are no human and animal participants.

\section{ORCID}

Jale Çatak

https://orcid.org/0000-0002-2718-0967

\section{References}

1. Sauve AA. NAD+ and vitamin B3: from metabolism to therapies.J Pharmacol Exp Ther. 2008;324: 883-93.

2. Ndaw S, Bergaentzle M, Aoude-Werner D, Hasselmann C. Enzymatic extraction procedure for the liquid chromatographic determination of niacin in foodstuffs. Food Chem. 2002;78:129-34.

3. Gehring W. Nicotinic acid/niacinamide and the skin. J Cosmet Dermatol. 2004;3:88-93.

4. Meyer-Ficca M. Niacin. Micronutrient Information Center, Linus Pauling Institute. http://pi.oregonstate.edu/infocenter/ vitamins/niacin/. Accessed 7 Dec 2018.

5. Nelson DL, Cox MM. Lehninger principles of biochemistry. 5th ed. New York, NY: Freeman and Company; 2008.

6. Kirkland JB. Niacin and carcinogenesis. Nutr Cancer. 2003;46:110-8.

7. Pollak N, Dolle C, Ziegler M. The power to reduce: pyridine nucleotides-small molecules with a multitude of functions. Biochem J. 2007;402:205-18.

8. Bellows L, Moore R. Water-soluble vitamins: B-complex and vitamin C. Food and Nutrition Series: Health. 2012;9:312.

9. Krehl WA, Teply LJ, Sarma PS, Elvehjem CA. Growth-retarding effect of corn in nicotinic acid-low rations and its counteraction by tryptophane. Science. 1945;101:489-90.
10. Schellack N. B-complex vitamin deficiency and supplementation: review. S Afr Pharm J. 2015;82:28-33.

11. Fukuwatari T, Shibata K. Effect of nicotinamide administration on the tryptophan-nicotinamide pathway in humans. Int Jvitam Nutr Res. 2007;77:255-62.

12. Altschul R, Hoffer A, Stephen JD. Influence of nicotinic acid on serum cholesterol in man. Arch Biochem Biophys. 1955;54:558-9.

13. Parsons WB. Treatment of hypercholesteremia by nicotinic acid progress report with review of studies regarding mechanism of action. Arch Intern Med. 1961;107:639-52.

14. Osmond H, Hoffer A. Massive niacin treatment in schizophrenia. Review of a nine year study. Lancet.1962;279:316-20.

15. Canner PL, Berge KG, Wenger NK, Stamler J, Friedman L, Prineas RJ, et al. Fifteen year mortality in Coronary Drug Project patients: long-term benefit with niacin. J Am Coll Cardiol. 1986;8:1245-55.

16. Capuzzi DM, Morgan JM, Brusco OA Jr, Intenzo CM. Niacin dosing: relationship to benefits and adverse effects. Curr Atheroscler Rep. 2000;2:64-71.

17. Kamanna VS, Kashyap ML. Mechanism of action of niacin on lipoprotein metabolism. Curr Atheroscler Rep. 2000;2:3646.

18. Carlson LA. Niaspan, the prolonged release preparation of nicotinic acid (niacin), the broad-spectrum lipid drug. Int J Clin Pract. 2004;58:706-13.

19. Marcus R, Coulston AM. Water-soluble vitamins. The vitamin B complex and ascorbic acid. In: Goodman LS, Gliman AG, Rall TW, Murad F, editors. Goodman \& Gilman's the pharmacological basis of therapeutics. 9th ed. New York, NY: McGraw-Hill; 1996. p. 1555-71.

20. Jacob RA, Swenseid ME. Niacin. In: Ziegler EE, Filer LJ, editors. Present knowledge in nutrition. 7th ed. Washington, DC: ILSI Press.; 1996. p. 185-90.

21. Gregory JF 3rd. Nutritional properties and significance of vitamin glycosides. Annu Rev Nutr. 1998;18:277-96.

22. Wall JS, Carpenter KJ. Variation in availability of niacin in grain products. Food Technol. 1988;198-204.

23. Kirby RW, Anderson JW, Sieling B, Rees ED, Chen WJ, Miller RE, et al. Oat-bran intake selectively lowers serum low-density lipoprotein cholesterol concentrations of hypercholesterolemic men. Am J Clin Nutr. 1981;34:824-9.

24. Mclntosh GH, Whyt J, McArthur R, Nestel PJ. Barley and wheat foods: influence on plasma cholesterol concentrations in hypercholesterolemic men. Am J Clin Nutr. 1991;53:1205-9.

25. Jenkins DJA, Kendall CWC, Faulkner DA, Nguyen T, Kemp T, Marchie A. Assessment of the longer-term effects of a dietary portfolio of cholesterol-lowering foods in hypercholesterol- 
emia. Am J Clin Nutr. 2006;83:582-91.

26. Shamliyan TA, Jacobs DR Jr, Raatz SK, Nordstrom DL, Keenan JM. Are your patients with risk of CVD getting the viscous soluble fiber they need? Few patients eat the right amount of fiber known to reduce CVD risks and events.J Fam Pract. 2006;55761-70.

27. Chen ZY, Jiao R, Ma KY. Cholesterol-lowering nutraceuticals and functional foods. J Agric Food Chem. 2008;56:8761-73.

28. Institute of Medicine (US) Standing Committee on the Scientific Evaluation of Dietary Reference Intakes and its Panel on Folate, Other B Vitamins, and Choline. Dietary reference intakes for thiamin, riboflavin, niacin, vitamin B6, folate, vitamin B12, pantothenic acid, biotin, and choline. Washington, DC: National Academies Press; 1998. https://www.ncbi.nlm. nih.gov/pubmed/23193625. Accessed 7 Dec 2018.

29. Sinclair A, Mann N, O'Connell S. The nutrient composition of Australian beef and lamb. Melbourne: RMIT; 1999.

30. Williams P. Nutritional composition of red meat. Nutr Diet. 2007;64:S113-9.

31. Hasan MN, Akhtaruzzaman M, Sultan MZ. Estimation of vitamins B-complex (B2, B3, B5 and B6) of some leafy vegetables indigenous to Bangladesh by HPLC method. JASMI. 2013;3:24-9.

32. Dawson KR, Unklesbay NF, Hedrick HB. HPLC determination of riboflavin, niacin, and thiamin in beef, pork, and lamb after alternate heat-processing methods. J Agric Food Chem. 1988;36:1176-9.

33. Vidal-Valverde $\mathrm{C}$, Reche A. Determination of available niacin in legumes and meat by high-performance liquid chromatography.J Agric Food Chem. 1991;39:116-21.

34. Agostini TS, Godoy HT. Simultaneous determination of nicotinamide, nicotinic acid, riboflavin, thiamin, and pyridoxine in enriched Brazilian foods by HPLC. J High Resolut Chromatogr. 1997;20: 245-8.

35. Rose-Sallin C, Blake CJ, Genoud D, Tagliaferri EG. Comparison of microbiological and HPLC-Fluorescence detection methods for determination of niacin in fortified food products. Food Chem. 2001;73:473-80.

36. Zafra-Gomez A, Garballo A, Morales JC, Garcia-Ayuso LE. Simultaneous determination of eight water-soluble vitamins in supplemented foods by liquid chromatography. J Agric Food Chem. 2006;54:4531-6.

37. Lahely S, Bergaentzle M, Hasselmann C. Fluorimetric determination of niacin in foods by high-performance liquid chromatography with post-column derivatization. Food Chem. 1999;65:129-33.

38. Ahmad MN. The effect of lentil on cholesterol-induced changes of serum lipid cardiovascular indexes in rats. Prog Nutr. 2017;19:48-56.

39. USDA. 2018. Wheat, durum. United States Department of Agriculture Nutrient Database, Basic Report: 20076. https:// ndb.nal.usda.gov/ndb/search/list. Accessed 8 Dec 2018.

40. TURCOMP. 2018. Wheat, durum. Turkish Food Composition Database. http://www.turkomp.gov.tr/food-119. Accessed 8 Dec 2018. 